\title{
EVENTOS EXTREMOS DE PRECIPITAÇÃO NA BACIA HIDROGRÁFICA DO RIO PIRATINI: RELAÇÃO COM ENOS E ESTUDO DE CASO
}

\author{
OGASSAWARA, Jéssica Fernanda - ogassawarajessica@gmail.com \\ Universidade Federal de Pelotas / UFPel \\ NUNES, André Becker - beckernunes@gmail.com \\ Universidade Federal de Pelotas / UFPel \\ RIQUETTI, Nelva Bugoni - nelva.bugoni@gmail.com \\ Universidade Federal de Pelotas / UFPel \\ Submetido em: 06/04/2020 \\ Aceito para publicação em: 22/03/2021 \\ Publicado em: $17 / 04 / 2021$ \\ DOI: http://dx.doi.org/10.5380/abclima.v28i0.72705
}

\begin{abstract}
RESUMO: O estudo sinótico e climatológico de eventos extremos torna-se importante, devido ao impacto que estes podem ocasionar frente à sociedade. Diante disso, o objetivo deste trabalho foi analisar eventos extremos de precipitação (percentil P99 da série histórica de acumulados diários) na bacia hidrográfica do rio Piratini (BHRP), no sul do Rio Grande do Sul (Brasil), entre 1981 e 2016, dando enfoque para o fenômeno ENOS (El Niño - Oscilação Sul). Foi analisado também um evento de enchente que ocorreu entre os dias 14 a 16 de fevereiro de 1983, atingindo as cidades de Pedro Osório e Cerrito. As cinco estações da bacia hidrográfica apresentaram entre 88 e 147 casos e uma correlação positiva, porém não significativa, entre os eventos extremos de chuva e o fenômeno El Niño. A análise do estudo de caso empregou a reanálise do ERA5 e detectou que o evento ocorreu devido a forçantes dinâmicas, como a presença de um cavado em altos níveis, e térmicas, como o escoamento de norte em baixos níveis, que acarretaram em uma ciclogênese extratropical próxima à costa.
\end{abstract}

PALAVRAS-ChAVE: El Niño, ERA5, Baixa do Noroeste Argentino, Jato de Baixos Níveis, Advecção de Vorticidade.

\section{EXTREME PRECIPITATION EVENTS IN THE WATERSHED BASIN OF PIRATINI RIVER: RELATIONSHIP WITH ENSO AND CASE STUDY}

\begin{abstract}
The synoptic and climatological study of extreme events becomes important, due to the impact that these can have on society. Therefore, the objective of this work was to analyze intense precipitation events (99th percentile of the historical series of daily accumulated) on the water basin of the Piratini River (BHRP), in the south of Rio Grande do Sul State (Brazil), from 1981 to 2016, regarding the relationship with the ENSO (El Niño - South Oscillation) phenomenon. It was also analyzed a flood event that took place between February 14th and 16th, 1983, reaching the cities of Pedro Osório and Cerrito. The five stations in the basin presented 88 to 147 cases and present a positive correlation, but not significant, between the events of extreme rainfall and the El Niño phenomenon. The analysis of the case study employed ERA5 re-analysis dataset and found out the event occurred due to dynamic forcing, such as the presence of a trough at high levels, and thermal, as the northerlies low levels flow, which resulted in an extratropical cyclogenesis near the coast.
\end{abstract}

KEYWORDS: El Niño, ERA5, Northwestern Argentinean Low, Low Level Jet, Vorticity Advection.

EVENTOS EXTREMOS DE PRECIPITACION EN LA CUENCA HIDROGRÁFICA DEL RÍO PIRATINI: RELACIÓN CON ENOS Y ESTUDIO DE CASO 


\begin{abstract}
El estudio sinóptico y climatológico de eventos extremos se vuelve importante, debido al impacto que estos pueden generar en la sociedad. En este contexto, el objetivo de este estudio fue analizar eventos extremos de precipitación (percentil P99 de la serie histórica de acumulación diaria) en la cuenca hidrográfica del río Piratini (BHRP), en el sur de Rio Grande do Sul, entre 1981 y 2016, dando énfasis en la relación con el fenómeno ENOS (El Niño - Oscilación Sur). Fue analizado también un evento de inundación que ocurrió entre los días 14 y 16 de febrero de 1983, alcanzando a las ciudades de Pedro Osório y Cerrito. Las cinco estaciones en la cuenca hidrográfica presentaron entre 88 y 147 casos y una correlación positiva, pero no significativa, entre los eventos de lluvia extrema y el fenómeno El Niño. El análisis del estudio de caso utilizó el reanálisis del ERA5 e identificó que el evento ocurrió debido a fuerzas dinámicas, como la presencia de una vaguada en altos niveles, y térmicas, como el flujo del norte en bajos niveles, lo que resultó en una ciclogénesis extratropical cerca de la costa.
\end{abstract}

PALABRAS ClAVE: El Niño, ERA5, Baja del Noroeste Argentino, Jet de Bajos Niveles, Advección de Vorticidad.

\title{
INTRODUÇÃO
}

As mudanças climáticas têm provocado alterações no regime hidrológico, influenciando na ocorrência de eventos extremos de precipitação (MIKHAILOVA et al., 2012). Segundo Ghumman et al. (2012), este fenômeno resulta em inúmeros problemas relacionados a enchentes em bacias hidrográficas, gerando expressivos prejuízos de caráter material, social e ambiental.

Nos últimos anos, $90 \%$ dos desastres têm sido relacionados com as condições climáticas e os tipos de desastres naturais mais frequentes no Brasil foram as enchentes, com 59\% dos registros totais (BRUNDA; NYAMATHI, 2015). Conforme o Relatório de Conjuntura da Agência Nacional de Águas (ANA, 2016), em 2015 foram publicados 212 decretos de situação de emergência (SE) ou estado de calamidade pública (ECP) em 195 municípios brasileiros, devido à ocorrência de enchentes. Destes, 64 estão no Estado do Rio Grande do Sul (RS). Diante disto, estudos voltados a análise de eventos extremos no Estado do RS têm sido amplamente realizados com intuito de verificar as possíveis causas para tais acontecimentos. Como por exemplo, o estudo de Pereira e Nunes (2018), que consta uma análise climática dos eventos de precipitação que tem potencial para causar enchentes nos principais centros urbanos do RS, e o estudo de Dorneles et al. (2020) que teve como objetivo analisar um evento extremo de chuva que atingiu as regiões sul e nordeste do RS.

O ENOS é um fenômeno de grande escala que resulta da interação entre oceano e atmosfera, caracterizado por anomalias na Temperatura da Superfície do Mar (TSM) no Oceano Pacifico Equatorial e por fases quente e fria, conhecidas como El Niño e La Niña. Tanto o El Niño quanto a La Niña provocam mudanças na circulação atmosférica em escala regional e global, gerando anomalias climáticas e alterando o regime térmico e hídrico em diversas regiões do mundo (ROPELEWSKI; HALPERT, 1987; KILADIS; DIAZ, 1989; GRIMM et al. 2000; BERLATO; FONTANA, 2003; LIMA; NUNES, 2018).

O Estado do RS, que apresenta precipitação pluvial bem distribuída ao longo do ano, sofre alterações com o ENOS. Na região Sul do Brasil a fase quente do ENOS (El Niño) determina, em geral, ocorrência de precipitação pluvial acima da média climatológica, especialmente na primavera e no outonoinverno do ano seguinte, e a fase fria (La Niña), precipitação pluvial abaixo da média climatológica, ocorrendo nos mesmos períodos de El Niño (STUDZINSKI, 1995; FONTANA; BERLATO,1997; GRIMM et al., 1998). Além da precipitação 
média, trabalhos como Grimm e Tedeschi (2009), Nunes e Da Silva (2013), Pereira e Nunes (2018), entre outros, identificaram relação direta entre o El Niño e eventos extremos de chuva no Sul do país. No geral, entende-se por chuva intensa os eventos de grandes taxas de precipitação, normalmente causados por sistemas de mesoescala (BARLOW et al., 2019).

A formação dos Sistemas Convectivos de Mesoescala (SCM), na primavera e no verão, caracterizados por intensos fluxos verticais turbulentos de calor, são os principais causadores de eventos extremos de chuvas na região Sul do Brasil (TEIXEIRA; SATYAMURTY, 2007). Além disso, as frentes frias, principalmente no inverno, e os Vórtices Ciclônicos de Altos Níveis (VCAN) também são responsáveis por precipitações de grande intensidade e concentradas na região, porém com menor frequência (MONTEIRO; FURTADO, 1995; NASCIMENTO, 2005; TEIXEIRA; SATYAMURTY, 2007; GRIMM; TEDESCHI, 2009; NUNES; PEREIRA, 2017).

Dentre os SCM pode-se citar as linhas de instabilidade (LI), que são zonas de instabilidade na qual uma série de tempestades estão dispostas de forma alinhada, e os Complexos Convectivos de Mesoescala (CCM) sendo sistemas responsáveis por fortes chuvas e rajadas de vento (VELASCO; FRITSCH, 1987; REBOITA et al., 2012). O elemento principal para a formação dos CCMs é a presença de um Jato de Baixos Níveis (JBN) que contribui para a intensificação da convergência de umidade na região do CCM (REBOITA et al. 2010). Conforme Reboita (2008), a disponibilidade de umidade favorece a precipitação que, por consequência, libera calor latente que aquece a coluna atmosférica e induz convergência na baixa troposfera. Assim, a associação deste processo termodinâmico com um processo dinâmico favorece as formações dos ciclones, ou seja, nas ciclogêneses.

A compreensão dos fenômenos meteorológicos e a análise dos sistemas que contribuem para a formação de um evento extremo são de suma importância para o melhoramento da previsão do tempo e emissão de alertas, visando diminuir os prejuízos à sociedade. Sendo assim, o objetivo do trabalho foi analisar o aspecto climatológico dos eventos extremos de chuvas em uma bacia hidrográfica localizada no Estado do RS, com o intuito de verificar se estes eventos estão mais frequentes, e também analisar a relação dos mesmos com o fenômeno ENOS, visto que acabam corroborando na ocorrência de cheias e inundações nos municípios atingidos. Apresenta-se neste trabalho, a análise sinótica de um estudo de caso de enchente de grande impacto na cidade de Pedro Osório e Cerrito, localizadas no exutório da bacia. Este evento atingiu aproximadamente $80 \%$ do território de ambas as cidades, apresentando marcas históricas do nível da água, que alcançou $26 \mathrm{~m}$ (cota acima do nível médio do mar). Os danos ocasionados pelo evento foram mais de 300 residências destruídas, cerca de 4.000 pessoas desabrigadas, com registro de uma vítima fatal e inúmeros animais mortos, assim como também perdas severas na lavoura e pecuária e a destruição da ponte férrea em Pedro Osório (TELLES, 2002; RECKZIEGEL, 2007).

\section{MATERIAIS E MÉTODOS}

O estudo foi conduzido na bacia hidrográfica do rio Piratini (BHRP), localizada na região noroeste do Estado do RS (Figura 1). A bacia possui área de drenagem de $4.700 \mathrm{~km}^{2}$ e é um dos principais afluentes do Canal São Gonçalo, 
importante via navegável que une a Laguna dos Patos à Lagoa Mirim. O clima da região, conforme a classificação de Köppen, é do tipo Cfa, ou seja, subtropical úmido, sem estação seca, caracterizado por verões quentes e chuvas bem distribuídas ao longo do ano (ALVARES et al., 2013).

Inicialmente foram analisados os dados diários de precipitação de estações pluviográficas monitoradas pela Agência Nacional de Águas (ANA), distribuídas ao redor e ao longo da BHRP. Em seguida foram traçados os Polígonos de Thiessen (THIESSEN; ALTER, 1911) sobre a região das estações pluviográficas e sobre a área da BHRP com o intuito de verificar a influência das estações em relação à bacia em estudo. Das estações pluviográficas que influenciaram os eventos de chuva na BHRP, foram priorizadas aquelas que possuíam séries históricas com pelo menos 30 anos de observação, conforme as recomendações da Organização Meteorológica Mundial (OMM), e também aquelas que apresentaram poucos períodos de falhas. No total, foram consideradas cinco estações pluviográficas (Figura 1), sendo estas: Canguçu (3152003), Ferraria (3153004), Pinheiro Machado (3153008), Estação Experimental do Piratini (3153021) e Herval (3253004). Destaca-se que a bacia foi delimitada à montante da seção de controle (exutório) Pedro Osório (88641000), também monitorada pela ANA.

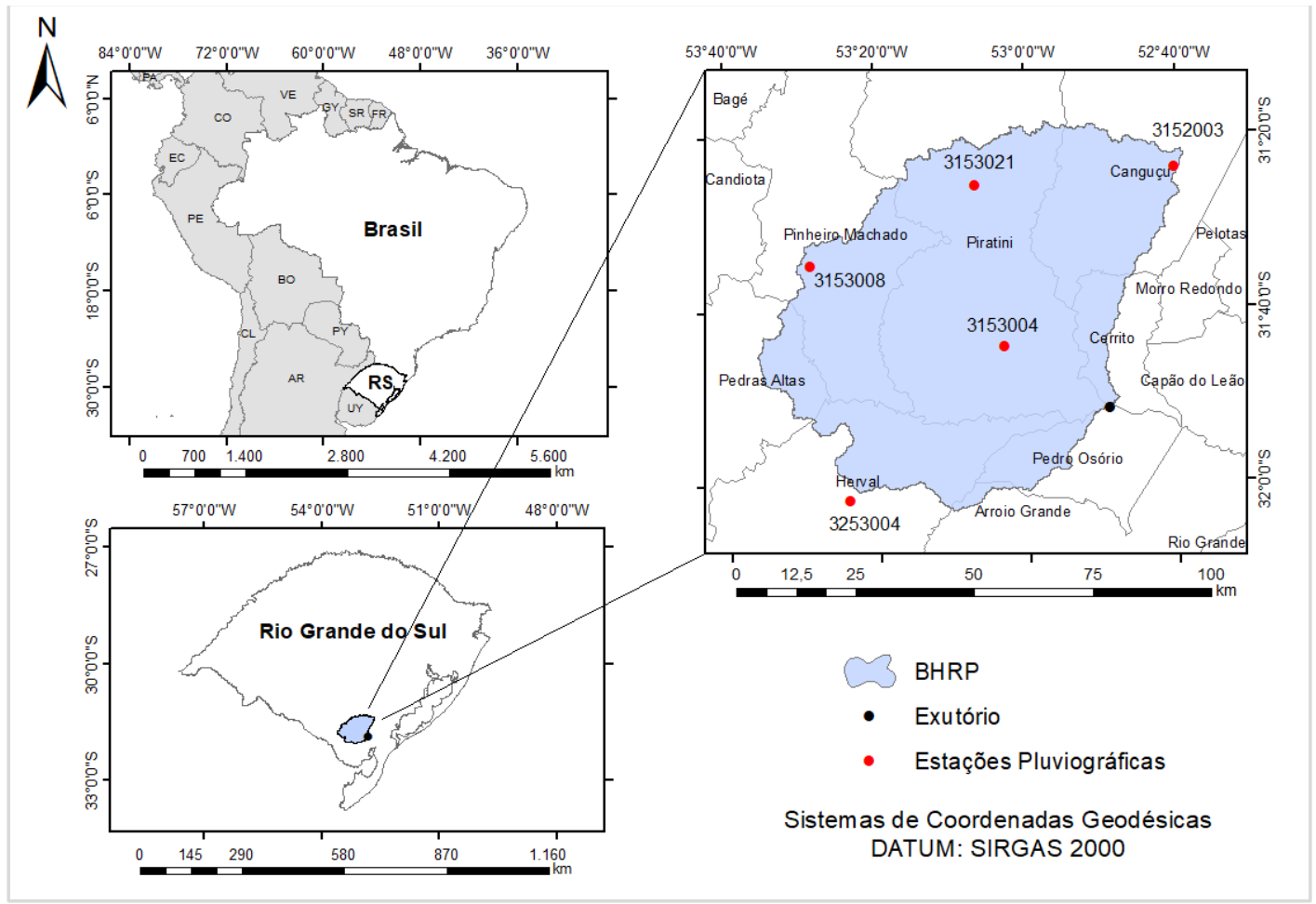

Figura 1 - Localização da bacia hidrográfica do rio Piratini (BHRP) e das estações pluviográficas sob responsabilidade da Agência Nacional de Águas (ANA).

Visando a análise climatológica dos dados, os mesmos foram organizados de forma a constituir uma série histórica do período de 1981 a 2016. Neste estudo, considerou-se como evento extremo de chuva os acumulados diários que ultrapassaram o percentil 99 (P99) da série histórica de cada estação. 
Salienta-se que os anos de 2007, 2009 e 2010 foram descartados da série histórica, devido ao grande número de falhas observado. Já as ocorrências de eventos ENOS no período analisado foram obtidas no site da NOAA (National Oceanic and Atmospheric Administration), por meio do índice ONI (Oceanic Niño Index) contabilizando-se o número de meses com ocorrência de eventos El Niño, La Niña e Neutros.

Primeiramente, foi realizada uma análise temporal dos casos de eventos extremos de chuvas, para verificar uma possível tendência linear ao longo dos anos em relação à ocorrência destes eventos. Foi aplicado o teste de MannKendall (MANN, 1945; KENDALL, 1975) para aferir se a tendência observada era significativa ou não. Posteriormente, foram calculados os coeficientes de correlação linear, cuja significância estatística foi estimada aplicando o teste TStudent (WILKS, 2011), a fim de constatar se existia relação entre as ocorrências de eventos extremos de chuvas e o índice ONI, para cada estação pluviográfica.

Com as séries históricas organizadas, foi possível computar o volume pluviográfico médio anual e o volume pluviográfico médio mensal anual para a BHRP de aproximadamente $1.600 \mathrm{~mm}$ e $133 \mathrm{~mm}$. Foi também analisado um evento extremo de chuva que ocorreu entre os dias 14, 15 e 16 de fevereiro de 1983, o qual chegou a um volume médio de 194,64mm na BHRP, valor este acima da média mensal anual citada anteriormente.

Devido ao grande impacto causado por este evento de chuva nas cidades de Pedro Osório e Cerrito, foi realizada uma análise sinótica do mesmo por meio de campos meteorológicos obtidos de dados de reanálise do ERA5 (HERSBACH et al., 2020). Esta reanálise, que é a quinta geração do modelo do European Centre for Medium-Range Weather Forecasts (ECMWF), possui resolução horizontal de $0.25^{\circ}$, resolução temporal de 1 h e 137 níveis verticais.

\section{RESULTADOS E DISCUSSÃO ANÁLISE CLIMATOLÓGICA}

Na Tabela 1 é possível observar a cidade das estações pluviográficas utilizadas no presente estudo, o valor de P99 das séries históricas diárias de cada estação, bem como o número total de ocorrência de eventos extremos de chuva e o valor máximo diário observado em cada série histórica após a aplicação do P99.

Tabela 1 - Cidade das estações pluviográficas, valor do percentil 99\% (P99), número total de ocorrências de eventos extremos de chuva e o máximo valor diário aplicando o P99 para cada série histórica no período de 1981-2016.

\begin{tabular}{ccccc}
\hline $\begin{array}{c}\text { Estações } \\
\text { pluviométricas }\end{array}$ & Cidade & $\begin{array}{c}\text { P99 } \\
(\mathrm{mm})\end{array}$ & $\begin{array}{c}\text { Total de } \\
\text { eventos }\end{array}$ & $\begin{array}{c}\text { Máximo diário } \\
(\mathrm{mm})\end{array}$ \\
\hline 3152003 & Canguçu & 56,5 & 147 & 130,8 \\
3253004 & Pedras Altas & 58,2 & 90 & 138,0 \\
3153008 & Pinheiro Machado & 59,5 & 102 & 153,0 \\
3153004 & Piratini & 59,9 & 120 & 216,8 \\
3153021 & Piratini & 60,4 & 88 & 278,0 \\
\hline
\end{tabular}


Percebe-se que as estações 3152003 e 3153021 apresentaram mais e menos casos de eventos extremos, respectivamente. Ambas estão localizadas em regiões de relevo acidentado, que por sua vez acaba potencializando as diferenças de eventos extremos, mesmo entre estações próximas, devido à chuva orográfica. Além disso, este resultado não surpreende, haja visto que são valores de P99 diametralmente opostos - ou seja, a estação que apresenta mais casos é a que necessita de menor precipitação $(56,5 \mathrm{~mm})$ para que seja detectado evento extremo de chuva. Contudo, como verificado em outras estações, esta relação não é direta. Na Figura 2 são apresentados os números de casos de eventos extremos mensais para cada estação pluviográfica. Em média, foram contabilizados 109 eventos extremos ao longo dos anos analisados para as cinco estações. Além disso, com exceção de março, abril, agosto e novembro a estação 3152003, como esperado, foi a que apresentou mais casos mensais. Todavia, a quantificação dos casos entre as demais estações não apresentou muitas diferenças.

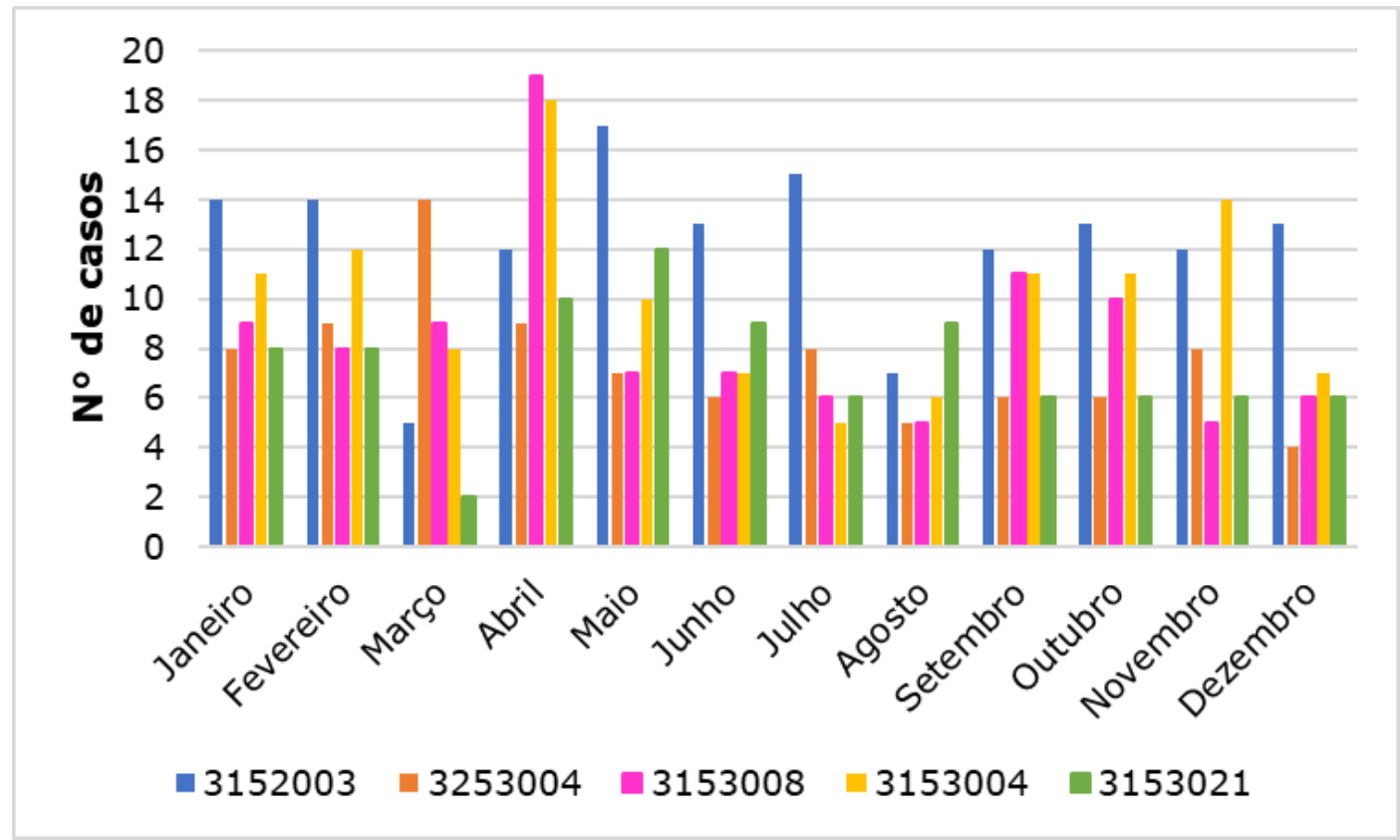

Figura 2 - Número de casos de eventos extremos mensais considerando os limiares do P99 para cada estação pluviográfica no período de 1981-2016.

A Figura 3 mostra predominância dos casos de eventos extremos contabilizados no outono, considerado nos meses de abril, maio e junho (AMJ), para a maioria das estações pluviográficas (Canguçu (3152003) apresentou 42 eventos; Pinheiro Machado (3152008), 33 eventos; Ferraria (3153004), 35 eventos e Estação Experimental do Piratini (3153021), 31 eventos). Isto pode ser confirmado pela média das estações meteorológicas (barra cinza da Figura 3). A exceção ficou para a estação Herval (3253004), com 31 eventos extremos contabilizados no verão (janeiro, fevereiro e março - JFM), estação do ano com mais casos de eventos extremos depois do outono. Via de regra, a estação do ano que apresentou menos casos de eventos extremos foi o inverno. Sansigolo e Kayano (2010) analisaram seis estações pluviográficas espalhadas pelo RS (Bagé, Passo Fundo, Porto Alegre, Santa Maria, Santa Vitória do Palmar e São Luís Gonzaga) no período de 1913-2006 e detectaram aumento de casos de 
eventos extremos relacionados a chuvas intensas principalmente durante o verão. Já no estudo de Pereira e Nunes (2018) para as cidades de Porto Alegre, Pelotas, Caxias do Sul e Santa Maria no período de 1961-2013, os autores observaram mais casos de eventos extremos no inverno, resultado oposto do analisado no estudo em questão.

Berlato e Cordeiro (2017), analisaram diversos estudos publicados após o ano de 2000 sobre as tendências climáticas observadas no RS e, concluíram, que houve aumento do volume e dos totais de dias com chuvas intensas no verão e também nas estações de transição primavera e outono. No presente estudo, as estações do ano que apresentaram mais casos de eventos extremos foram o outono e o verão. Grimm et al. (1998) relatam que variações bimodais significativas de precipitação ocorrem em várias partes do Sul do Brasil. Esse comportamento é provavelmente causado pela interferência de dois regimes adjacentes: as monções de verão e as condições de inverno de latitude média, que são responsáveis pelos picos das estações chuvosas em janeiro e julho. A variação bimodal domina o sudoeste do Rio Grande do Sul, com estações chuvosas no outono e primavera, e o nordeste do Rio Grande do Sul, com máximos no inverno e verão.

A média dos eventos extremos de cada série histórica é apresentada em quinquênios ao longo do período de 1981 à 2005 e em quadriênio nos últimos anos do período em análise, de 2006 à 2016 (Figura 4). Posteriormente foram geradas as tendências lineares para cada estação pluviográfica (Figura 4). As equações de cada tendência linear podem ser observadas na Tabela 2.

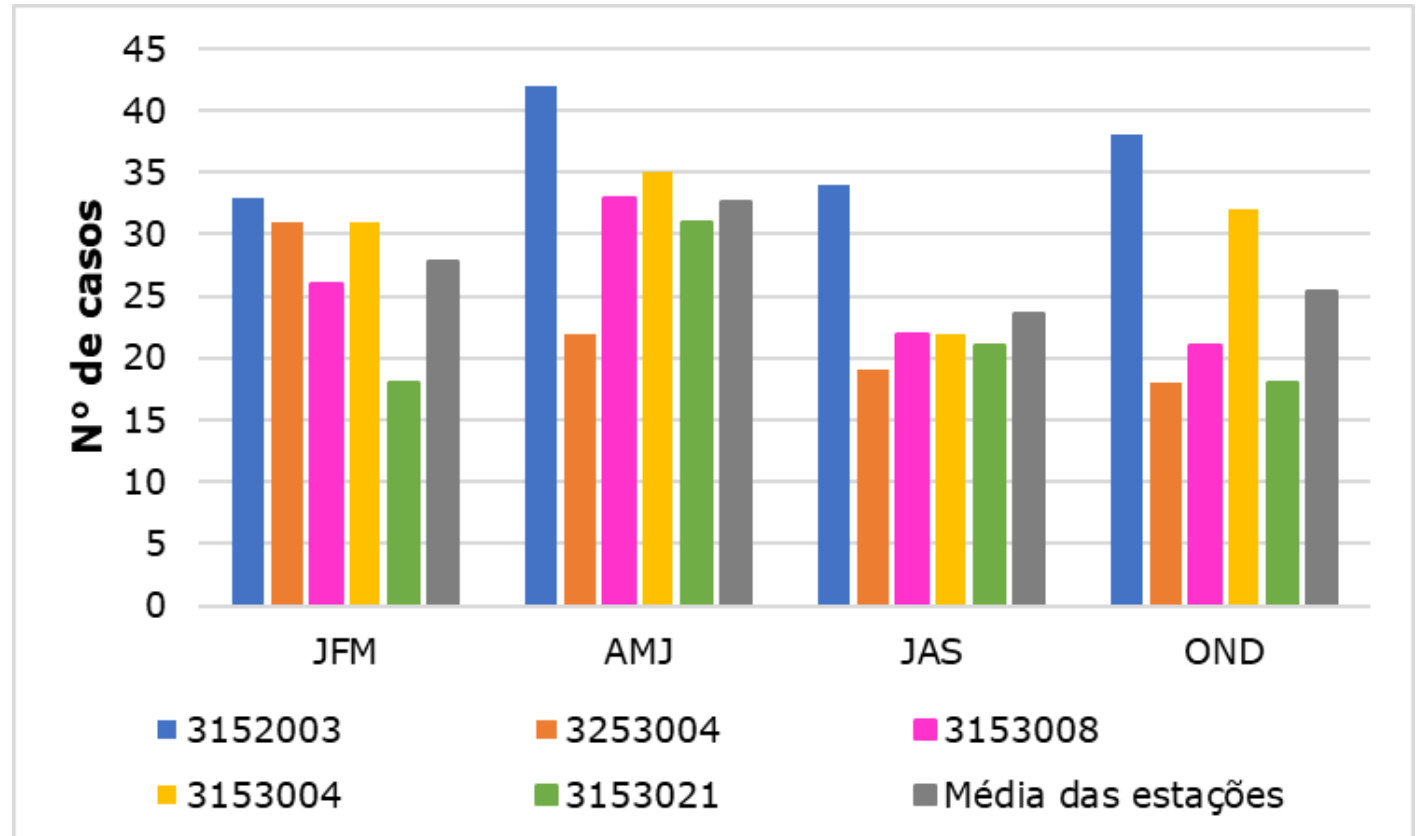

Figura 3 - Número médio de casos de eventos extremos, considerando as estações do ano, considerando os limiares do P99 para cada estação pluviográfica no período de 1981-2016. 


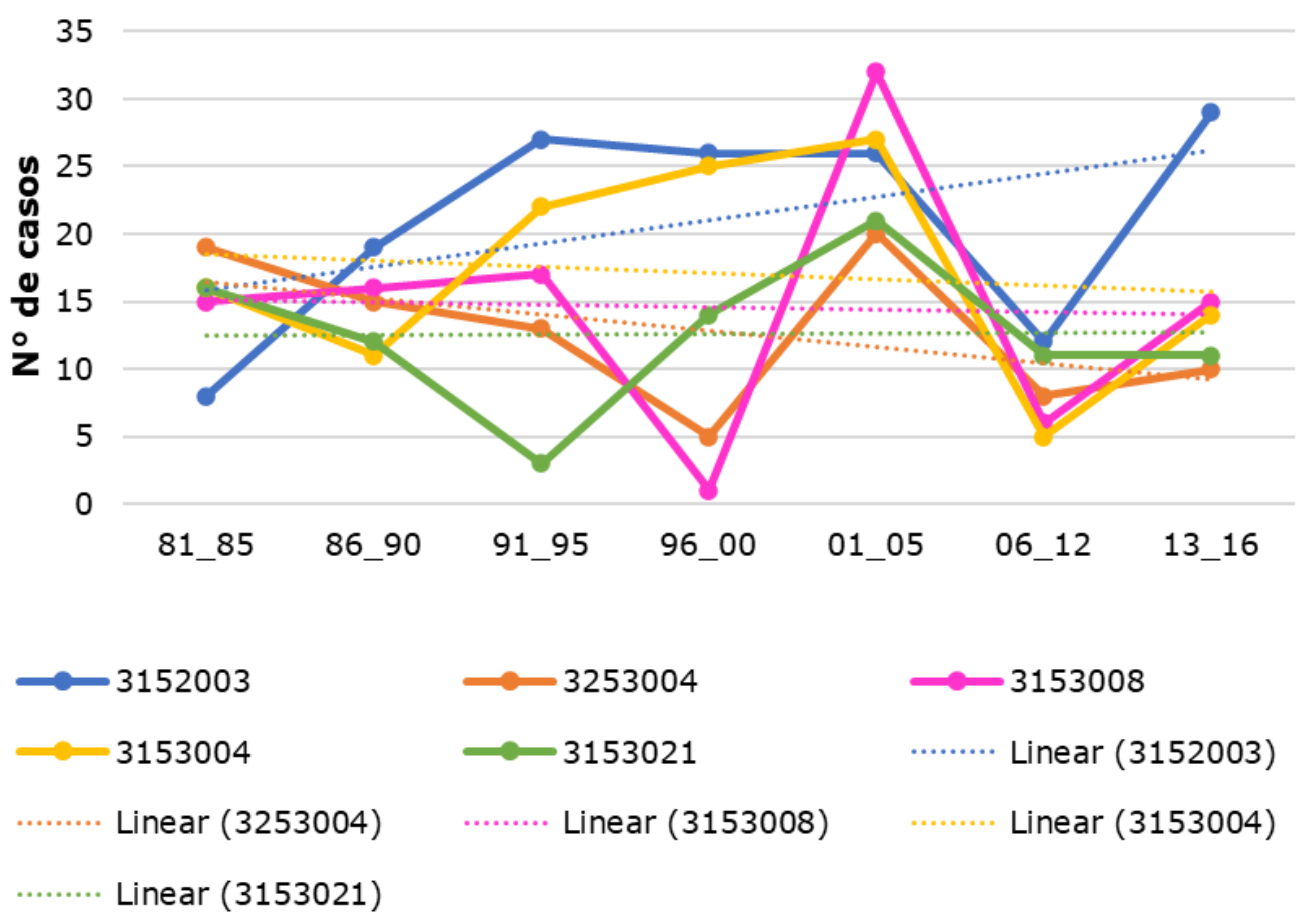

Figura 4 - Média dos eventos extremos em quinquênio (1981-2005) e quadriênio (20062016), considerando os limiares do P99 para cada estação pluviográfica. O período 2006 2012 se refere a quadriênio porque foram desconsiderados os anos de 2007, 2009 e 2010 da série histórica, devido às falhas nos dados.

Analisando a Tabela 2, constata-se que três das cinco estações pluviográficas (3253004, 3153008, 3153004) apresentam tendência negativa, ou seja, retratam um declínio nas ocorrências dos eventos extremos ao longo do tempo analisado, entretanto, esses declínios são sutis. As estações pluviográficas 3152003 e 3153021 apresentam tendências positivas, porém, a estação 3152003 se destaca por apresentar maior ascensão de eventos extremos. Quando calculado o p-valor do teste de Mann-Kendall a um nível de significância de $95 \%$, averiguou-se que somente para a estação pluviográfica 3153004 houve tendência significativa, visto que o valor encontrado foi inferior à significância adotada $(a=0,05)$.

Tabela 2 - Equações das tendências lineares aplicadas aos somatórios dos quinquênios dos eventos extremos para cada estação pluviográfica.

\begin{tabular}{cccc}
\hline $\begin{array}{c}\text { Estação } \\
\text { Pluviográfica }\end{array}$ & Equação & $\begin{array}{c}\text { Tendência } \\
\text { Linear }\end{array}$ & $\begin{array}{c}\text { Mann-Kandall } \\
(p \text {-valor })\end{array}$ \\
\hline 3152003 & $y=1,71 x+14,14$ & Positiva & 0,335 \\
3253004 & $y=-1,21 x+17,71$ & Negativa & 0,251 \\
3153008 & $y=-0,18 x+15,21$ & Negativa & 0,445 \\
3153004 & $y=-0,46 x+19,00$ & Negativa & 0,003 \\
3153021 & $y=0,04 x+12,43$ & Positiva & 0,315 \\
\hline
\end{tabular}

As correlações lineares entre os eventos extremos e o índice ONI para cada estação pluviográfica, foram todas positivas, evidenciando a relação direta entre o El Niño e eventos extremos de chuva, com valores de: 0,35 para a 
estação 3152003; 0,16 para a estação 3153004; 0,24 para a estação 3153008; 0,20 para a estação 3153021 e 0,22 para a estação 3253004. Grimm et al. (1998) relatam que a forte relação entre a ocorrência de eventos extremos de precipitação com anos de El Niño é devido à intensificação dos CCM na região Sul do Brasil, os quais são responsáveis, principalmente, pelo pico da estação chuvosa na primavera. Além disso, os autores relatam que esta intensificação está provavelmente associada ao fortalecimento do jato subtropical sobre a região durante os eventos El Niño. Outros estudos (CABALLERO et al., 2018; TEDESCHI et al., 2015; GRIMM et al., 1998; FONTANA; BERLATO, 1997 também abordam a influência do fenômeno ENOS nos sistemas meteorológicos, os quais acabam corroborando na ocorrência de eventos extremos de precipitação na região Sul do Brasil, sendo estes as baixas térmicas, frentes frias, ciclone extratropical e o processo de ciclogênese.

Entretanto, conforme metodologia sugerida em Dancey e Reidy (2006), os valores encontrados no presente estudo indicam que as correlações entre eventos extremos e o índice ONI são fracas. Aplicando o teste T-Student a um nível de significância de $95 \%$, foi constatado que estatisticamente não possuem correlação significativa. O fato da correlação linear ter sido classificada como fraca e não significativa pode ser devido ao critério de utilizar o P99 nas séries históricas, o que reduziu muito a quantidade de eventos estremos de chuvas contabilizadas e, consequentemente, a correlação entre as variáveis. Além disso, estes valores já eram esperados, visto que tais eventos são influenciados por diversos aspectos da geografia local.

\section{ANÁLISE SINÓTICA}

Estudos como os de Grimm et al. (1998) e Berlato e Fontana (2003) relatam que em anos de El Niño, uma importante consequência no clima do Sul do Brasil é o aumento das chuvas na região, o que, dependendo da duração e da altura precipitada pode causar enchentes, e também episódios de temporais, com granizo e intensas rajadas de ventos. Foi realizada uma análise sinótica do caso de enchente ocorrido na BHRP, mais precisamente nas cidades de Pedro Osório e Cerrito, entre os dias 14, 15 e 16 de fevereiro de 1983 (fase quente do ENOS), visando a compreensão dos fenômenos e sistemas meteorológicos que contribuíram para a formação de tal evento extremo de chuva. Cabe destacar que a precipitação diária na bacia, considerando a média entre as cinco estações pluviográficas, foi de $43,4 \mathrm{~mm}, 131,6 \mathrm{~mm}$ e $19,7 \mathrm{~mm}$ para os dias 14/02, 15/02 e $16 / 02$, respectivamente, e que a média para apenas o mês de fevereiro, entre as cinco estações e para o período estudado na análise climática (1981-2016), foi de 143,6mm. Percebe-se que somente em um dia (15/02) choveu aproximadamente o que se esperava para o mês de fevereiro, mais precisamente, cerca de $92 \%$ do valor médio contabilizado.

A Figura 5 apresenta o campo de pressão ao nível médio do mar (PNMM) e altura geopotencial em $500 \mathrm{hPa}$, para todos os dias do evento analisado, às 00 UTC e às 12 UTC. Observa-se a Baixa do Noroeste Argentino (BNOA) (SELUCHI et al., 2003; ESCOBAR; SELUCHI, 2012; SELUCHI; SAULO, 2012) estendendose até o RS durante todo o período, formando um cavado no sentido noroestesudeste e ciclogênese na costa a partir do dia 15 (Figura 5d). Conforme Gan e Rao (1991); Reboita (2008) e Reboita et al. (2012), entre a costa uruguaia e a do Sul/Sudeste do Brasil são frequentemente afetadas por ciclones 
extratropicais que causam ventos fortes, precipitação e redução de temperatura. Além disso, Reboita (2008) relata que em anos de El Niño, há uma variabilidade maior de atividades ciclogenéticas. Este fato indica instabilidade em superfície e, consequentemente, possibilidade de chuvas intensas. A evolução da BNOA em uma ciclogênese extratropical típica é observada em vários trabalhos, inclusive nos referentes a eventos de chuva intensa, como Caballero et al. (2018). A BNOA é descrita como um sistema presente no verão quando os fluxos de calor são predominantes, sendo modulada pelas atividades transientes e de advecção térmica horizontal vinculada à atividade frontal, e sua existência deve-se ao excesso de temperatura na baixa troposfera (LICHTENSTEIN, 1980; SELUCHI; SAULO, 2012).

No campo de altura geopotencial em 500 hPa (Figura 5), ao longo dos dias observa-se a presença de um cavado transiente em níveis médios, indicando advecção de vorticidade ciclônica (AVC) sobre o RS. Tal condição, conforme a teoria quase-geostrófica, acarreta em movimento ascendente e queda da altura geopotencial em superfície e, consequentemente, favorece instabilidade (HOLTON, 2004). A advecção de vorticidade foi a forçante dinâmica que alimentou o cavado em superfície, resultando na ciclogênese extratropical.

Observa-se na Figura 6a a presença do jato subtropical em $250 \mathrm{hPa}$ atuando sobre a região em estudo, favorecendo a intensificação de instabilidade nos sistemas de baixa pressão. Grimm et al. (1998); Zimmermann (2017) e Lima e Nunes (2018) relatam que durante os eventos ENOS, em geral, La Niña enfraquece o jato subtropical, enquanto El Niño intensifica. O cavado de altos níveis (Figura 6) amplifica-se com o tempo, fortalecendo a AVC. Além disso, observa-se que, durante todo o período, o Estado do RS esteve sob difluência do escoamento em altos níveis, característica muitas vezes associada ao aumento da severidade da instabilidade em superfície (SANDERS, 1993; BLUESTEIN, 1993), inclusive sobre a região de estudo (NUNES, 2017). Kousky e Cavalcanti (1984) descrevem que durante o El Niño em 1983, na região Sul do Brasil, ocorreu a intensificação do jato subtropical e sua influência no aumento da chuva.

O campo de linha de corrente em $850 \mathrm{hPa}$ (Figura 7), inicialmente mostra o escoamento de norte devido ao anticiclone semipermanente do Atlântico. Posteriormente, observa-se que no transcorrer dos dias há um aumento da magnitude desse vento de norte do continente, atingindo sua máxima intensificação ao leste dos Andes, na região da BNOA, o que influencia no transporte de calor e umidade de baixas latitudes para a região de estudo. A conjunção entre a BNOA (Figura 5) e o cavado em altos níveis (Figura 6), identificados nesta análise, é comumente encontrada em eventos extremos de chuva no Sul do Brasil, como relatado nos estudos de Teixeira e Satyamurty (2007), Riquetti et al. (2018) e Dorneles et al. (2020). 

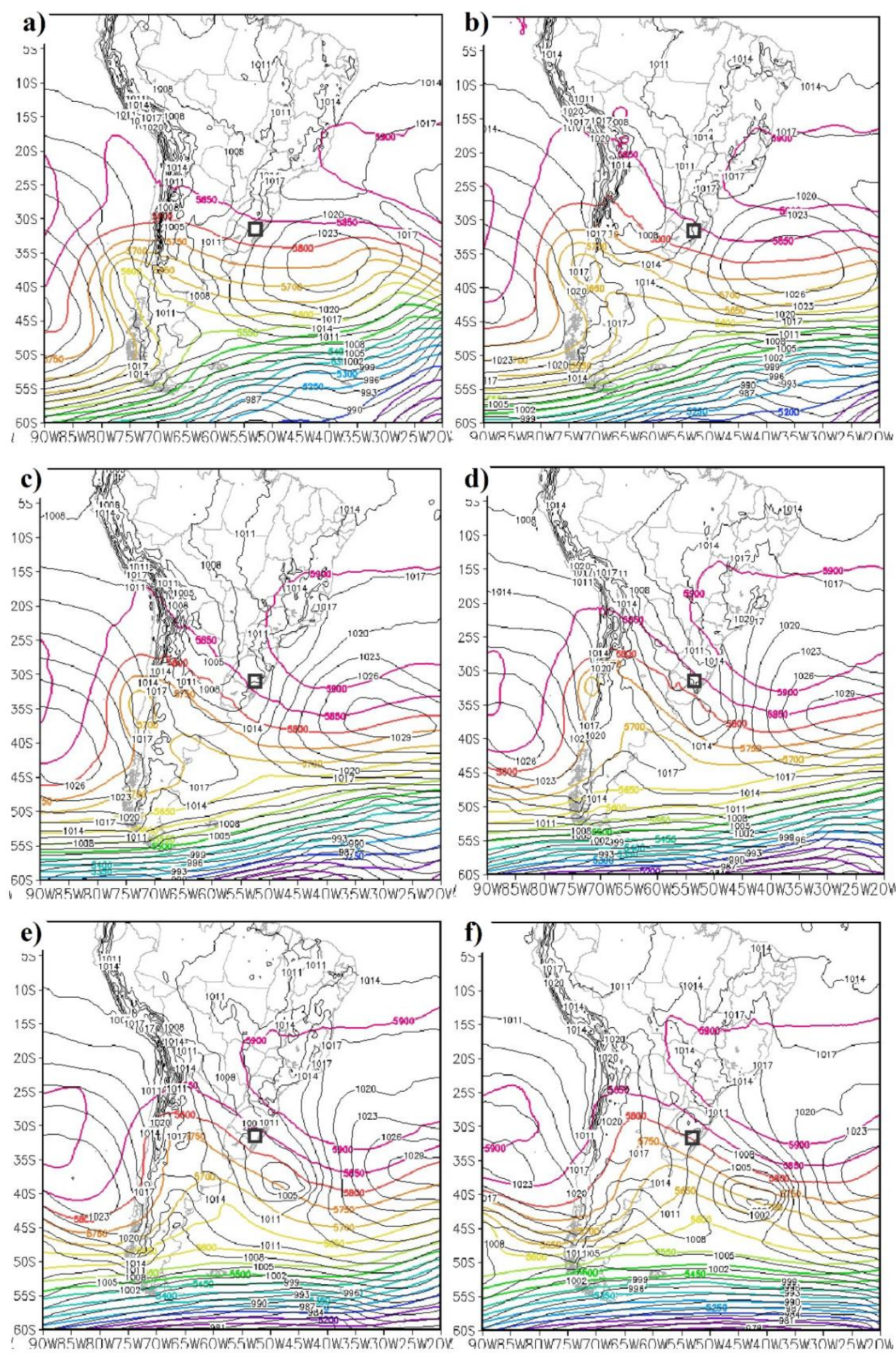

Figura 5 - Campo de PNMM (linhas em preto, em hPa) e altura geopotencial (linhas coloridas, em mgp) em 500hPa, sendo: a) 14/02/1983 às 00 UTC, b) 14/02/1983 às 12 UTC, c) $15 / 02 / 1983$ às 00 UTC, d) 15/02/1983 às 12 UTC, e) 16/02/1983 às 00 UTC e f) 16/02/1983 às 12 UTC. O retângulo preto indica a localização da área em estudo. 

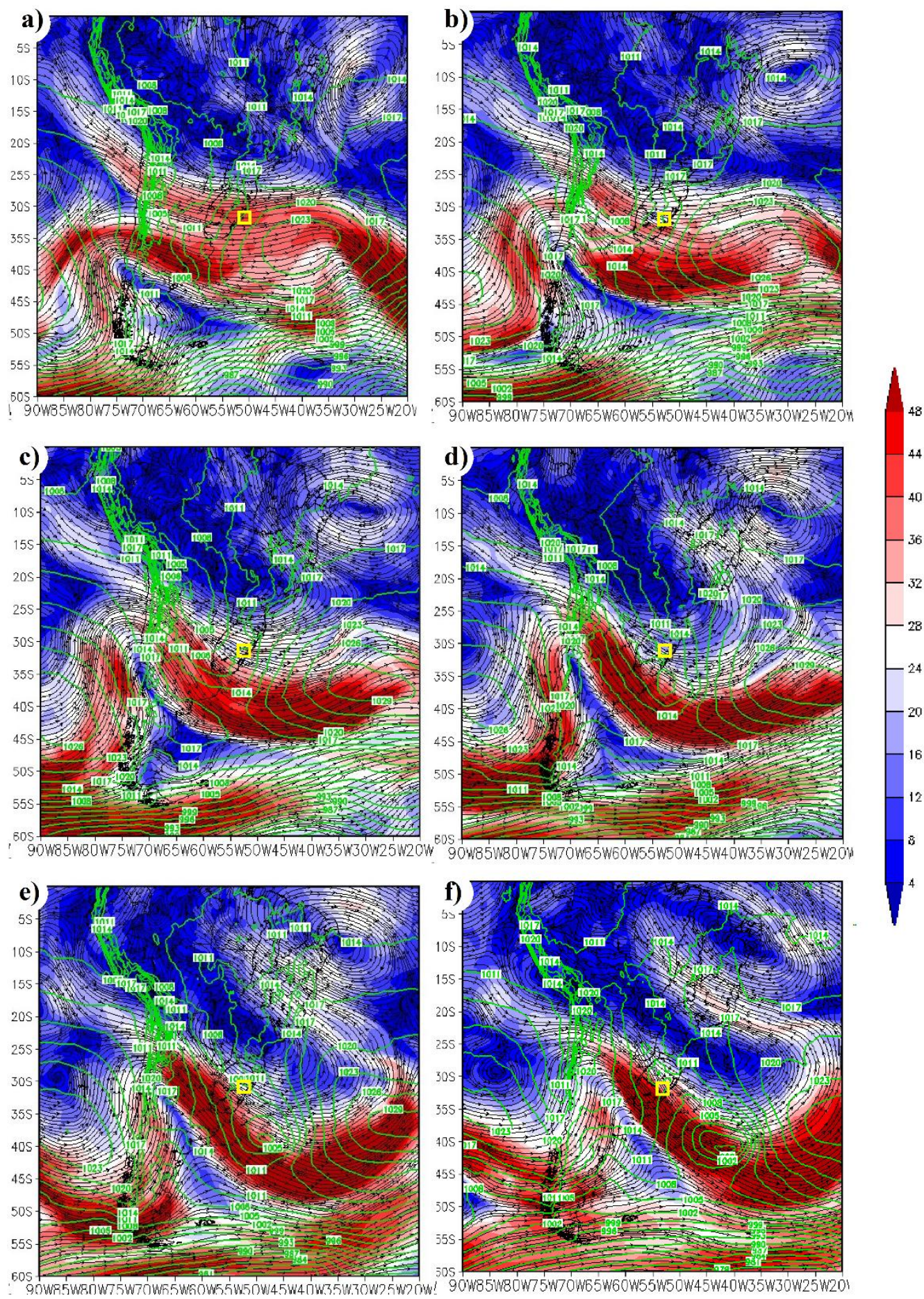

Figura 6 - Campo de PNMM (contorno em verde, em hPa), linha de corrente (linhas em preto) e magnitude do vento (sombreado, em m s${ }^{-1}$ ) em $250 \mathrm{hPa}$, sendo: a) 14/02/1983 às 00 UTC, b) $14 / 02 / 1983$ às 12 UTC, c) $15 / 02 / 1983$ às 00 UTC, d) $15 / 02 / 1983$ às 12 UTC, e) $16 / 02 / 1983$ às 00 UTC e f) $16 / 02 / 1983$ às 12 UTC. O retângulo amarelo indica a localização da área em estudo. 

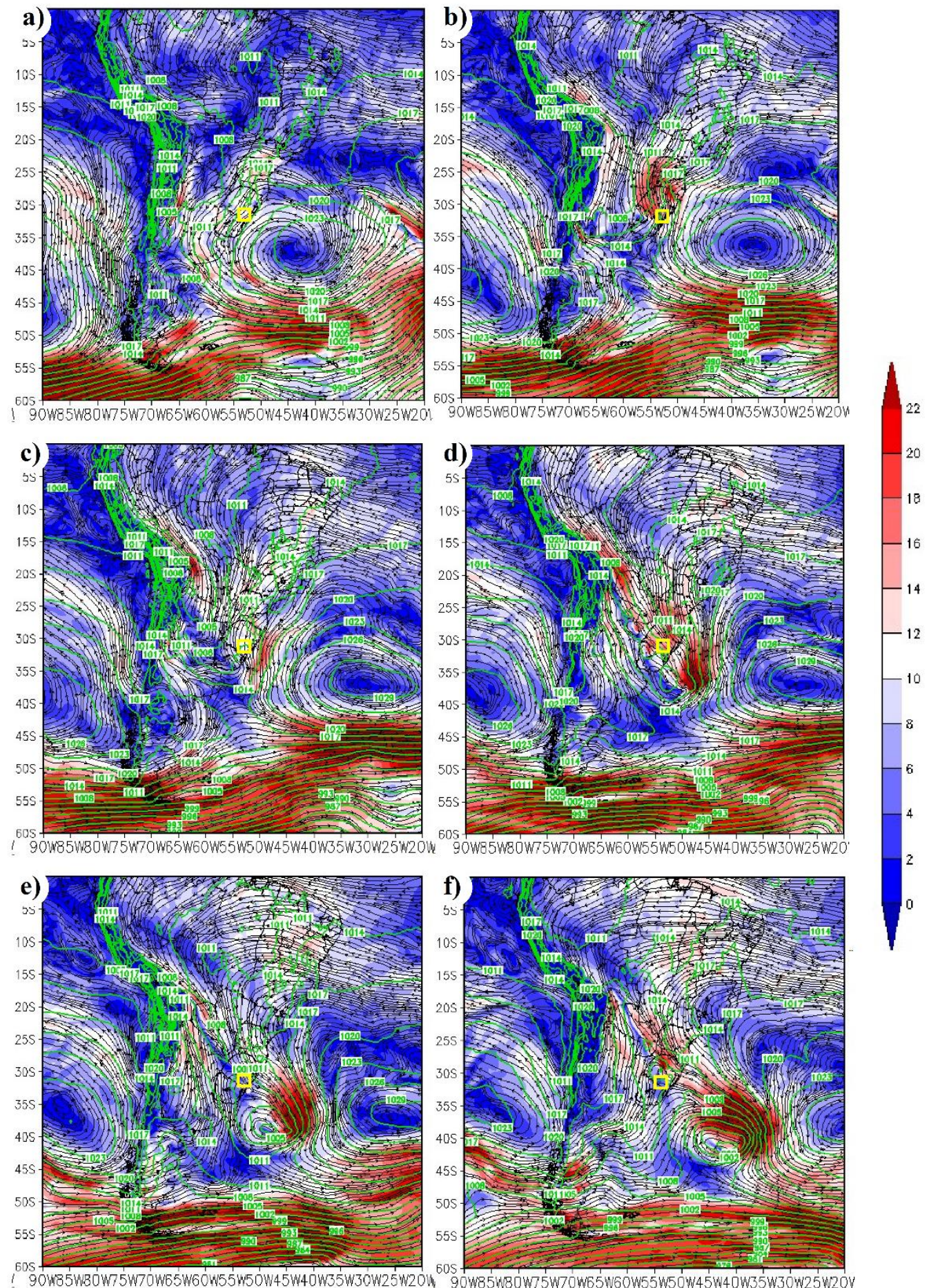

Figura 7 - Campo de PNMM (contorno em verde, em hPa), linha de corrente (linhas em preto) e magnitude do vento (sombreado, em m s${ }^{-1}$ ) em $850 \mathrm{hPa}$, sendo: a) 14/02/1983 às 00 UTC, b) $14 / 02 / 1983$ às 12 UTC, c) 15/02/1983 às 00 UTC, d) 15/02/1983 às 12 UTC, e) $16 / 02 / 1983$ às 00 UTC e f) $16 / 02 / 1983$ às 12 UTC. O retângulo amarelo indica a localização da área em estudo. 
Além disso, pode-se inferir que a presença do JBN nos dias do evento propiciou a intensificação da BNOA. Nota-se na Figura 7 a presença de ventos de norte em $850 \mathrm{hPa}$ com velocidades acima de $12 \mathrm{~m} \cdot \mathrm{s}^{-1}$ na região de estudo, indicando a ocorrência do JBN, conforme critérios de Bonner (1968). De acordo com Silva e Ambrizzi (2006) e Silva et al. (2009), existe uma relação entre a frequência e intensidade dos JBNs com o fenômeno El Niño. Uma possível explicação para isso seria a intensificação dos ventos alísios de nordeste sobre o continente em anos de El Niño, favorecendo os JBNs. Marengo et al. (2004), Salio et al. 2007 e Saulo et al. (2007) descrevem a contribuição do JBN no transporte de massas de ar quente e úmido tropical da Amazônia para o Sul do Brasil e norte da Argentina, propiciando assim condições para advecção e desenvolvimento de SCM e provocando a intensificação da precipitação nessas regiões. Estudos recentes indicam que as maiores taxas de precipitação média estão ocorrendo em função da presença dos JBNs e em maiores extensões (AMARAL, 2014).

A Figura 8 apresenta os campos de PNMM e velocidade vertical ômega em $500 \mathrm{hPa}$. Nota-se o predomínio de movimento ascendente durante todo o período do evento de enchente analisado, devido às forçantes de altos e baixos níveis citadas anteriormente, mesmo na fase final, quando o ciclone se afasta da região de estudo. Isto se deve ao escoamento de norte que permanece até o último estágio da análise (Figura $8 f$ ).

Nas Figuras 9 e 10 são apresentados os campos de umidade relativa e temperatura do ar em $850 \mathrm{hPa}$, respectivamente. Pode-se observar que sempre há presença de umidade sobre a região em estudo, atingindo máximos valores para todos os dias de análise (Figura 9). Os valores elevados devem-se, principalmente ao transporte de umidade de norte em baixos níveis, sobre a área de influência da BNOA (SATYAMURTY et al., 1998; BEZERRA; NUNES, 2017), o que está associado a instabilidades na região Sul do Brasil (GRIMM, 2009), intensificando-se no dia 15/02 (Figuras 9c e 9d). Ainda é possível observar, em $850 \mathrm{hPa}$, a relação entre as variações positivas de umidade (Figuras 9c e 9d), as máximas velocidades do vento (Figuras 7c e 7d) oriundo da região Amazônica e os valores mais acentuados de temperatura (Figuras 10c e $10 \mathrm{~d}$ ) para o dia 15/02, o qual apresentou maior registro de chuva $(131,6 \mathrm{~mm})$ entre os três dias do evento analisado.

Nota-se que a região de estudo permaneceu sempre com valores altos de temperatura durante os três dias de análise, indicando a presença da massa tropical que frequentemente está associada com instabilidade (GRIMM, 2009). Além disso, no campo de vento em 850 hPa (Figura 7) identifica-se a advecção quente de norte durante praticamente todo o evento, um fator ciclogenético associado à instabilidade (HOLTON, 2004; REBOITA et al., 2017). 

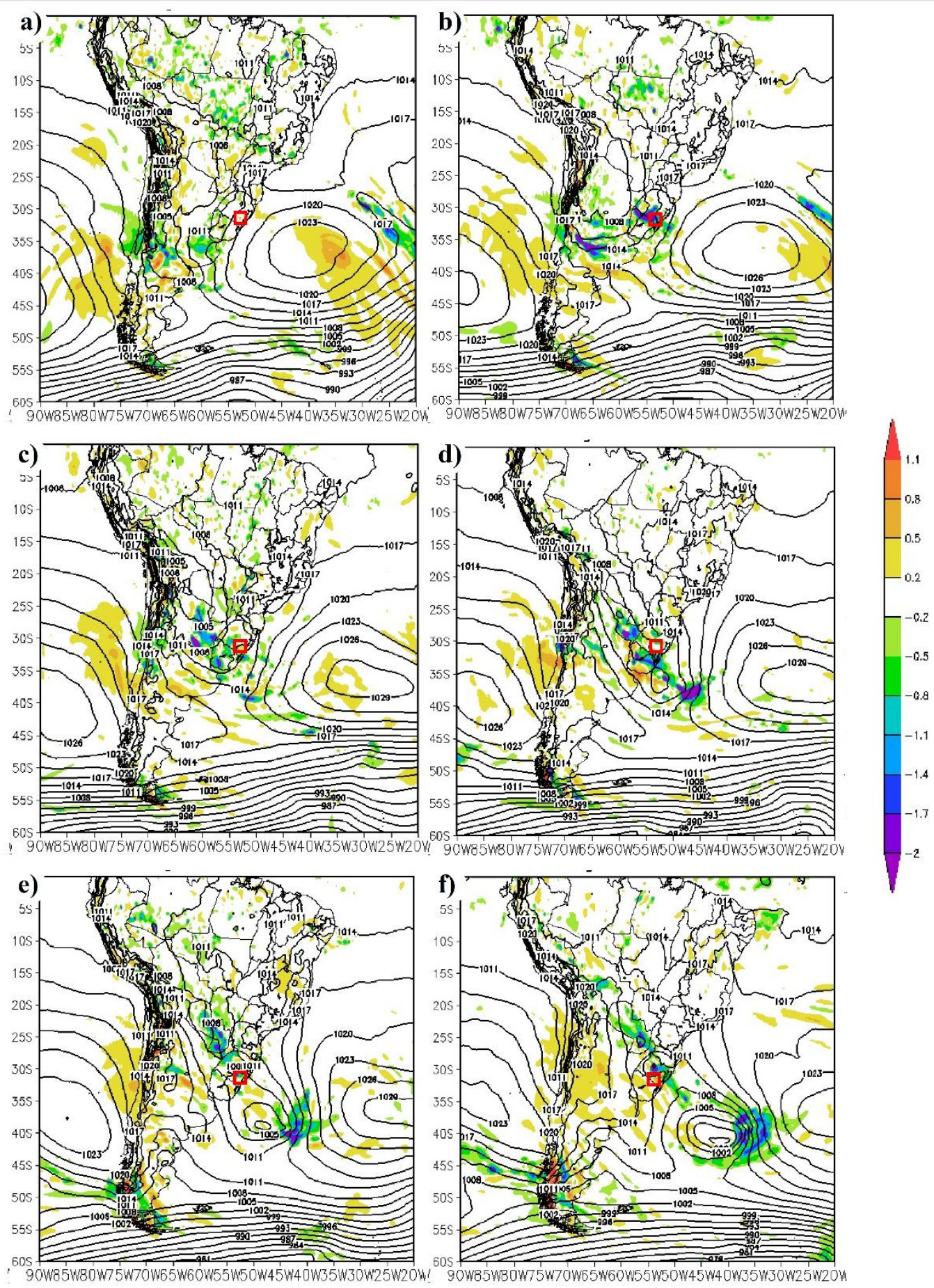

Figura 8 - Campo de PNMM (contorno em preto, em hPa) e velocidade vertical ômega (sombreado, em Pa s${ }^{-1}$ ) em 500 hPa, sendo: a) 14/02/1983 às 00 UTC, b) 14/02/1983 às 12 UTC, c) 15/02/1983 às 00 UTC, d) 15/02/1983 às 12 UTC, e) 16/02/1983 às 00 UTC e f) 16/02/1983 às 12 UTC. O retângulo vermelho indica a localização da área em estudo. 

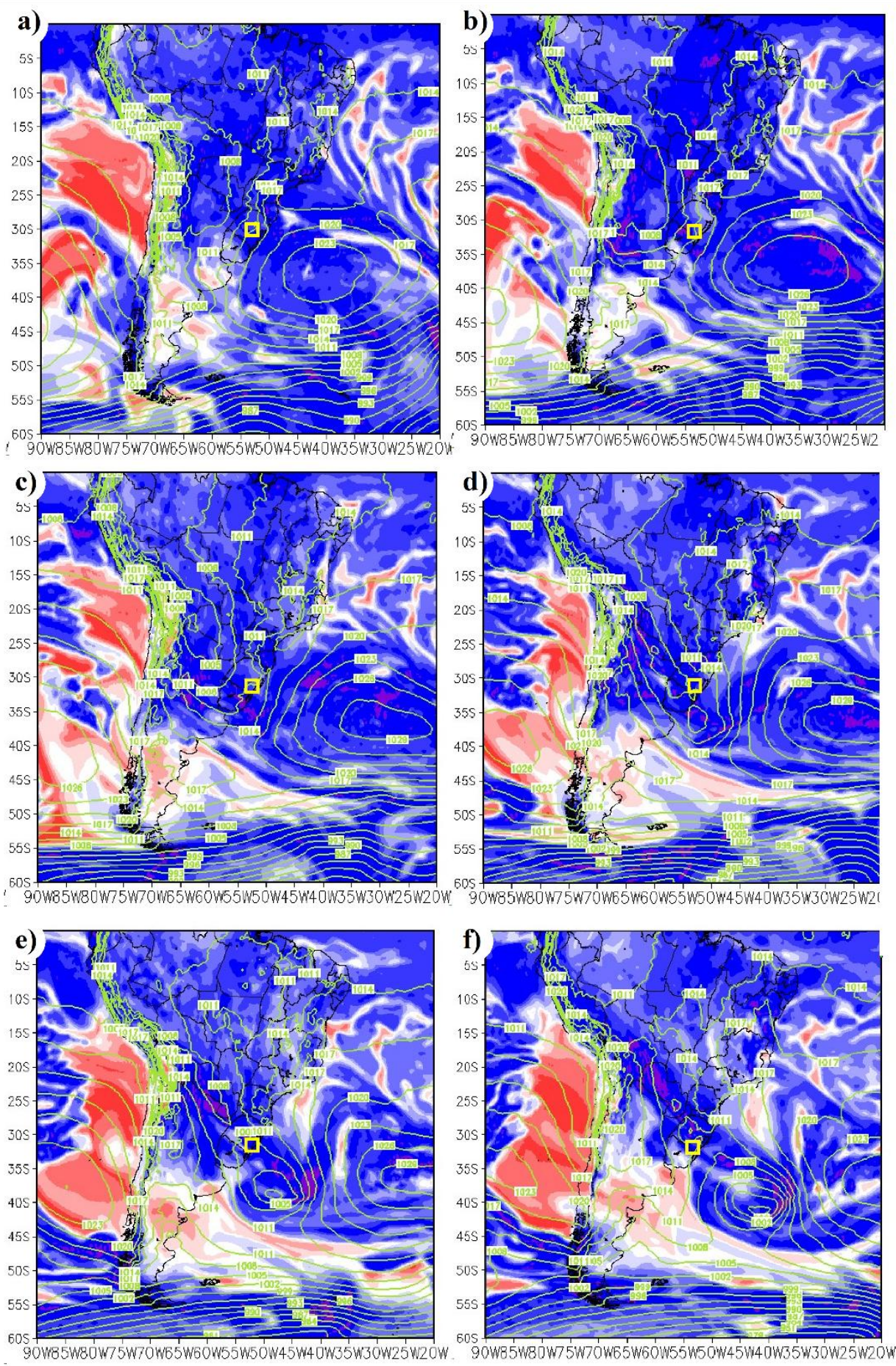

Figura 9 - Campo de PNMM (contorno em verde, em hPa) e umidade relativa do ar (sombreado, em \%) em $850 \mathrm{hPa}$, sendo: a) 14/02/1983 às 00 UTC, b) 14/02/1983 às 12 UTC, c) $15 / 02 / 1983$ às 00 UTC, d) $15 / 02 / 1983$ às 12 UTC, e) $16 / 02 / 1983$ às 00 UTC e f) 16/02/1983 às 12 UTC. O retângulo amarelo indica a localização da área em estudo. 

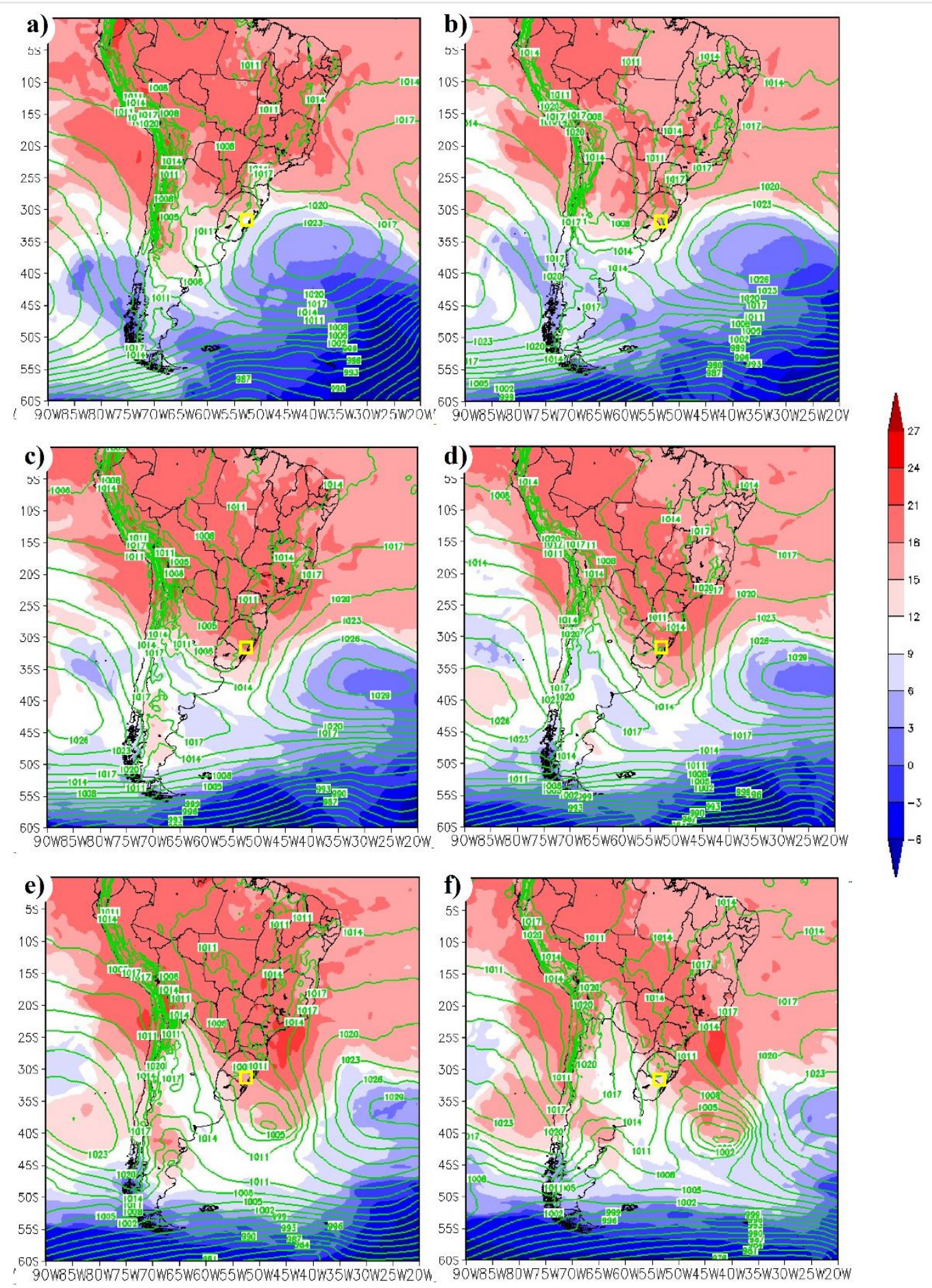

Figura 10 - Campo de PNMM (contorno em verde, em $\mathrm{hPa}$ ) e temperatura do ar (sombreado, em ${ }^{\circ} \mathrm{C}$ ) em $850 \mathrm{hPa}$, sendo: a) 14/02/1983 às 00 UTC, b) 14/02/1983 às 12 UTC, c) $15 / 02 / 1983$ às 00 UTC, d) $15 / 02 / 1983$ às 12 UTC, e) $16 / 02 / 1983$ às 00 UTC e f) 16/02/1983 às 12 UTC. O retângulo amarelo indica a localização da área em estudo. 


\section{CONCLUSÕES}

Em média foram contabilizados 109 eventos extremos de precipitação entre 1981 e 2016, analisados para cinco estações pluviográficas da BHRP. A estação do ano que apresentou mais e menos eventos foi o outono e o inverno, respectivamente, embora com pouca variação sazonal. Em relação ao ENOS, a correlação não foi significativa entre os eventos de P99 e os índices ONI. Entretanto, foi constatada uma correlação linear positiva entre estas variáveis, indicando uma relação direta entre as ocorrências dos eventos de chuvas extremas com as ocorrências do fenômeno El Niño, concordando com a literatura.

Para o estudo de caso, foi identificado um conjunto de forçantes que influenciou no desenvolvimento do sistema precipitante na BHRP e que acarretou nas enchentes em Pedro Osório e Cerrito entre os dias 14, 15 e 16 de fevereiro de 1983. Observou-se, à oeste do RS, a presença de um cavado em altos níveis, associado à advecção de vorticidade ciclônica, que indica instabilidade em superfície, e o aspecto difluente do escoamento em altos níveis. Em baixos níveis, observou-se temperatura e umidade relativa abundantes sobre o RS, devido ao escoamento de norte (com presença do JBN) associado à BNOA, o que evoluiu para um ciclone extratropical na costa, contribuindo para o evento de chuva intensa em ambas as cidades do estudo. Além disso, destaca-se que o comportamento dos sistemas atmosféricos analisados, como o jato subtropical e o JBN, aponta um evento de chuva típico para o ano de El Niño.

Como trabalho futuro, sugere-se realizar a climatologia sinótica de extremos de chuva na área de estudo para verificar se as características encontradas para o evento de fevereiro de 1983 serão similares a outros eventos extremos de chuva na BHRP. Ademais, sugere-se realizar a modelagem hidrológica na BHRP visando a análise do impacto dos eventos extremos de chuva nas vazões da bacia.

\section{AGRADECIMENTOS}

O presente trabalho foi realizado com apoio da Coordenação de Aperfeiçoamento de Pessoal de Nível Superior - Brasil (CAPES)-Código de Financiamento 001.

\section{REFERÊNCIAS BIBLIOGRÁFICAS}

ALVARES, C. A.; STAPE, J. L.; SENTELHAS, P. C.; GONÇALVES, J. L. M.; SPAROVEK, G. Koppen's climate classification map for Brazil. Meteorologische Zeitschrift, v. 22, n. 6, p. 711-728, 2013.

AMARAL, L. M. C. do. Análise de complexos convectivos ocorridos na região sul da América do Sul durante o período de 2005 a 2010. 2014. 204 f. Dissertação (Mestrado em Meteorologia). Instituto Nacional de Pesquisas espaciais - INPE, São José dos Campos, 2014. Disponível em: http://urlib.net/8JMKD3MGP5W34M/3G2T58B. Acesso em: 10 mar. 2020.

ANA - AGÊNCIA NACIONAL DE ÀGUAS. Conjuntura dos Recursos Hídricos no Brasil: Informe 2016. Brasília, 2016. 95 p. Disponível em: 
http://www.snirh.gov.br/portal/snirh/centrais-de-conteudos/conjuntura-dosrecursos-hidricos/informe-conjuntura-2016.pdf. Acesso em: 06 abr. 2020.

BARLOW, M.; GUTOWSKY JR, W. J.; GYAKUM, J. R.; KATZ, R. W.; LIM, Y.K.; SCHUMACHER, R. S.; WEHNER, M. F.; AGEL, L.; BOSILOVICH, M.; COLLOW, A. ; GERSHUNOV, A.; GROTJAHN, R.; LEUNG, R.; MILRAD, S.; MIN, S.K. North American Extreme Precipitation Events and Related Large-Scale Methods, Dynamics, Modeling, and Trends. Climate Dynamics. v. 53, p. 6835-6875, 2019.

Berlato, M. A.; FONTANA, D. C. El Niño e La Niña: Impactos no clima, na vegetação e na agricultura do Rio Grande do Sul: Aplicações de previsões climáticas na agricultura. Porto Alegre: Ed. da UFRGS 2003. 110 p.

BERLATO, M. A.; CORDEIRO, A. P. A. Sinais de mudanças climáticas globais e regionais, projeções para o século XXI e as tendências observadas no Rio Grande do Sul: uma revisão. Agrometeoros, v. 25, n. 2, p. 273-302, 2017.

BLUESTEIN, H. B. Synoptic-Dynamic Meteorology in Midlatitudes. Volume II: Observations and theory of weather systems. Oxford: Oxford University Press, 1993. 594 p.

BONNER, W. D. Climatology of the low level jet. Monthly Weather Review, v. 96, n. 12, p. 833-850, 1968.

BRUNDA, G. S.; NYAMATHI, S. J. Derivation and Analysis of Dimensionless Hydrograph and S Curve for Cumulative Watershed Area. Aquatic Procedia, v. 4, p. 964-971, 2015.

CABALLERO, C. B.; OGASSAWARA, J. F.; DORNELES, V. R.; NUNES, A. B. A precipitação pluviométrica em Pelotas/RS: tendência, sistemas sinóticos associados e influência da ODP. Revista Brasileira de Geografia Física, v. 11, n.4, p. 1429-1441, 2018.

CAVALCANTI, I. F. A.; KOUSKY, V. E. Frentes Frias sobre o Brasil. In: CAVAlCANTI, I. F. A. et al. Tempo e Clima no Brasil. São Paulo: Oficina de Textos, 2009. p. 135-147.

CERA, J.; FERRAZ, S. E. T. Variações climáticas na precipitação no sul do Brasil no clima presente e futuro. Revista Brasileira de Meteorologia, v. 30, n. 1, p. $81-88,2015$.

COHEN, J. Statistical power analysis for the behavioral sciences. 2. ed. New York: Routledge, 2013. 400 p.

DORNELES, V. R.; RIQUETTI, N. B.; NUNES, A. B. Forçantes dinâmicas e térmicas associadas a um caso de precipitação intensa sobre o Rio Grande do Sul, Brasil. Revista Brasileira de Climatologia, v. 26, n. 16, p. 220-232, 2020.

ESCOBAR, G. C. J.; SELUCHI, M. E. Classificação sinótica dos campos de pressão atmosférica na América do Sul e sua relação com as baixas do Chaco e do noroeste argentino. Revista Brasileira de Meteorologia. v. 27, n. 3, p. 365-375, 2012.

FONTANA, D. C.; BERLATO, M. A. Influência do El Niño Oscilação Sul sobre a precipitação pluvial no Estado do Rio Grande do Sul. Revista Brasileira de Agrometeorologia, v. 5, p. 127-132, 1997. 
GAN, M. A.; RAO, V. B. Surface Cyclogenesis over South America. Monthly Weather Review, v. 119, p. 1293-1302, 1991.

GHUMMAN, A. R.; AHMAD, M. M.; HASHMI, H. N.; KAMAL, M. A. Development of geomorphologic instantaneous unit hydrograph for a large watershed. Environmental Monitoring and Assessment, v. 184, n. 4, p. 3153-3163, 2011.

GRIMM, A. M.; FERRAZ, S.E.T.; GOMES, J. Precipitation anomalies in Southern Brazil associated with El Niño and La Niña events. Journal of Climate, v. 11, p. 2863-2880, 1998.

GRIMM, A. M.; BARROS, V. R.; DOYLE, E. Climate variability in southern South America associated with El Niño and La Niña events. Journal of Climate, v. 13, n. 1, p. 35-58, 2000.

GRIMM, A. M. Clima da Região Sul do Brasil. In: CAVALCANTI, I. F. A. et al. Tempo e Clima no Brasil. São Paulo: Oficina de Textos, 2009. p. 259-275.

GRIMM, A. M.; TEDESCHI, R. G. ENSO and extreme rainfall events in South America. Journal of Climate, v. 22, p. 1589-1609, 2009.

HERSBACH, $\mathrm{H}$. et al. The ERA5 global reanalysis. Quarterly Journal of the Royal Meteorological Society, v. 146, p. 1999-2049, 2020. DOI: https://doi.org/10.1002/ qj.3803.

HOLTON, J.R. An Introduction to Dynamic Meteorology. 4. ed. Washington: Elsevier Academic Press, 2004. 553 p.

KENDALL, M. G. Rank correlation Methods. 4. ed. Londres: Charles Griffin, 1975. 202 p.

KILADIS, G. N.; DIAZ, H. F. Global climatic anomalies associated with extremes in the Southern Oscillation. Journal of Climate, v. 2, p. 1069-1090, 1989.

KOUSKY, V. E.; CAVALCANTI, I. F. A. Eventos Oscilação Sul - El Niño: Características, evolução e anomalias de precipitação. Ciência e Cultura, v. 36, n. 11, p. 1888-1899, 1984.

LICHTENSTEIN, E. R. La Depresión del Noroeste Argentino. Tese (Doutorado) 1980. 223 f. Facultad de Ciencias Exactas y Naturales, Universidad de Buenos Aires, $1980 . \quad$ Disponível em: http://digital.bl.fcen.uba.ar/Download/Tesis/Tesis_1649_Lichtenstein.pdf. Acesso em: 16 dez. 2020.

LIMA, M. V.; NUNES, A. B. Comportamento climático do balanço do vento térmico na América do Sul de acordo com os eventos ENOS: Estudo preliminar. Revista Brasileira de Geografia Física, v. 11, p. 728-744, 2018.

MANN, H. B. Non-parametric tests against trend. Econometrica, v. 13, n. 3, p. 245-259, 1945.

MARENGO, J.A.; SOARES, W.R.; SAULO, C.; NICOLINI, M. Climatology of the Low-Level Jet East of the Andes as Derived from the NCEP-NCAR Reanalyses: Characteristics and Temporal Variability. Journal of Climate, v. 17, n. 12, p. 2261-2280, 2004.

MARENGO, J. A.; SCHAEFFER, R.; PINTO, H. S.; ZEE, D. M. W. Mudanças climáticas e eventos extremos no Brasil. FBDS, 2009. 76p. Disponível em: 
http://www.fbds.org.br/cop15/FBDS_MudancasClimaticas.pdf. Acesso em: 08 mar. 2021.

MATZENAUER, R.; RADIN, B.; MALUF, J. R. T. O fenômeno ENOS e o regime de chuvas no Rio Grande do Sul. Agrometeoros, v. 25, n. 2, p. 323-331 2018.

MIKHAILOVA, M. V; MIKHAILOV, V. N.; MOROZOV, V. N. Extreme Hydrological Events in the Danube River Basin over the Last Decades. Water Resources and the Regime of Water Bodies, v. 39, n. 2, p. 161-179, 2012.

MONTEIRO, M. A; FURTADO, S. O clima do trecho Florianópolis - Porto Alegre: uma abordagem dinâmica. Geosul, v. 10, n. 19/20, p.117-133, 1995.

NASCIMENTO, E. L. Previsão de tempestades severas utilizando-se parâmetros convectivos e modelos de mesoescala: uma estratégia operacional adotável no Brasil. Revista Brasileira de Meteorologia, v. 20, p. 121-140, 2005.

NUNES, A. B.; DA SILVA, G. C. Climatology of extreme rainfall events in eastern and northern Santa Catarina State, Brazil: present and future climate. Revista Brasileira de Geofísica, v. 31, p. 413-425, 2013.

NUNES, A. B. Case Study of Upper Tropospheric Meteorological Systems on South America: Synoptic Analysis. Anuário do Instituto de Geociências, v. 40 , p. 70-82, 2017.

NUNES, A. B.; PEREIRA, R. S. Estimativa de eventos de precipitação com potencial para alagamentos urbanos no Rio Grande do Sul. In: NUNES, A. B.; MARIANO, G. L. (org.). Meteorologia em Tópicos. Pelotas: Clube de Autores, 2017. p. 273-314.

PEREIRA, R. S.; NUNES, A. B. Estudo climático dos eventos de precipitação associados a alagamentos urbanos no Estado do Rio Grande do Sul. Revista Brasileira de Geografia Física, v. 11, p. 2010-2017, 2018.

REBOITA, M. S.; GAN, M. A.; ROCHA, R. P. D.; AMBRIZZI, T. Regimes de precipitação na América do Sul: uma revisão bibliográfica. Revista brasileira de meteorologia, v. 25, n. 2, p. 185-204, 2010.

REBOITA, M. S. Ciclones Extratropicais sobre o Atlântico Sul: Simulação Climática e Experimentos de Sensibilidade. Tese (Doutorado) 2008. Instituto de Astronomia, Geofísica e Ciências Atmosféricas, Universidade de São Paulo. $2008 . \quad$ Disponível em: https://www.iag.usp.br/pos/sites/default/files/d_michelle_s_reboita_0.pdf. Acesso em: $16 \mathrm{dez} .2020$.

REBOITA, M. S.; KRUSCHE, N.; AMBRIZZI, T.; ROCHA, R. P. D. Entendendo o Tempo e o Clima na América do Sul. Terra e Didática, v. 8, p. 34-50, 2012.

RECKZIEGEL, B. W. Levantamento dos Desastres Desencadeados por Eventos Naturais Adversos no Estado do Rio Grande do Sul no Período de 1980 a 2005. Dissertação (Mestrado) 2007. Programa de Pós-Graduação em Geografia, Universidade Federal de Santa Maria. 2007.

RIQUETTI, N. B.; DORNELES, V. R.; NUNES, A. B. Estudo do caso de precipitação intensa sobre Foz do Iguaçu-PR em setembro de 2015. Revista Brasileira de Climatologia, v. 22, p. 589-606, 2018. 
ROPELEWSKI, C. F.; HALPERT, M. S. Global and regional scale precipitation patterns associated with the El Niño/Southern Oscillation. Monthly Weather Review, v. 115, p. 1606-1626, 1987.

SALIO, P.; NICOLINI, M.; ZIPSER, E. J. Mesoscale convective systems over South America and their relationship with the South American low-level jet. Monthly Weather Review, v. 135, p. 1290-1309, 2007.

SANDERS, F. Upper-Level Geostrophic Diffluence and Deepening of Surface Lows. Weather and Forecasting, v. 8, p. 339-344, 1993.

SANSIGOLO, C. A.; KAYANO, M. T. Trends of seasonal maximum and minimum temperatures and precipitation in Southern Brazil for the 1913-2006 period. Theoretical and Applied Climatology, v. 101, p. 209-216, 2010.

SATYAMURTY, P.; NOBRE, C. A.; SILVA DIAS, P. L. South America. In: KAROLY D. J.; Vicent, D. G. (org.). Meteorology of the Southern Hemisphere. American Meteorological Society, Meteorological Monographs, 1998. p. 119-139.

SAULO, C; RUIZ, J.; SKABAR, Y. G. Synergism between the Low-Level Jet and Organized Convection at Its Exit Region. Monthly Weather Review, 135, p. 1311-1326, 2007.

SELUCHI, M. E.; SAULO, A. C. Baixa do Noroeste Argentino e Baixa do Chaco: Características, diferenças e semelhanças. Revista Brasileira de Meteorologia, v. 27, n. 1, p. 49-60, 2012.

SILVA, G. A. M.; AMBRIZZI, T. Inter-El Niño variability and its impact on the South American low-level jet east of the Andes during austral summer - two case studies. Advances in Geosciences, v. 6, p. 283-287, 2006.

SILVA, G. A. M.; AMBRIZZI, T.; MARENGO, J. A. Observational evidences on the modulation of the South American Low Level Jet east of the Andes according the ENSO variability. Annales Geophysicae, v. 27, p. 645-657, 2009.

STUDZINSKI, C. D. Um estudo da precipitação na região Sul do Brasil e sua relação com os oceanos Pacífico e Atlântico tropical e sul. 1995. Dissertação (Mestrado em Meteorologia). Instituto Nacional de Pesquisas espaciais - INPE, São José dos Campos, 1995.

TEDESCHI, R. G.; GRIMM, A. M.; CAVALCANTI, I. F. A. Influence of Central and East ENSO on extreme events of precipitation in South America during austral spring and summer. International Journal of Climatology, v. 35, n. 8, p. 2045-2064, 2015.

TEIXEIRA, M. S.; SATYAMURTY, P. Dynamic and Synoptic Characteristics of Heavy Rainfall Episodes in Southern Brazil. Monthly Weather Review, v. 115, p. 598-617, 2007.

TELLES, R. M. Inundações Urbanas nos municípios de Pedro Osório e Cerrito. Dissertação (Mestrado) 2002. 74 f. Programa de Pós Graduação em Geografia, Universidade Federal do Rio Grande do Sul. 2002.

THIESSEN, A.; ALTER, J. C. Precipitation averages for large areas. Climatological Data For July. Monthly Weather Review, v. 39, n. 10, p. 1082-1084, 1911.

VELASCO, I.; FRITSCH, J. M. Mesoscale convective complexes in the Americas. Journal of the Geophysical Research, v. 92, p. 9591-9613, 1987. 
ZIMMERMANN, D. F. R. SUBTROPICAL JET CLIMATOLOGY OVER SOUTH AMERICA. Dissertação (Mestrado) 2017. Instituto de Astronomia, Geofísica e Ciências Atmosféricas, Universidade de São Paulo. 2017. Disponível em: https://www.iag.usp.br/pos/meteorologia/english/dissertacoestestes/climatologi a-do-jato-subtropical-na-am\%C3\%A9rica-do-sul. Acesso em: 08 MAR. 2021. 